\title{
Factors Associated with Psychiatric Comorbidity in Depression Patients in Primary Health Care in Chile
}

\author{
Alfredo Cancino (D), ${ }^{1,2}$ Marcelo Leiva-Bianchi, ${ }^{3}$ Carlos Serrano, ${ }^{3}$ \\ Soledad Ballesteros-Teuber, ${ }^{1}$ Cristian Cáceres, ${ }^{3}$ and Verónica Vitriol $\oplus^{1,4}$ \\ ${ }^{1}$ Medicine School, Universidad de Talca, Talca, Chile \\ ${ }^{2}$ Communal Mental Health Program, Primary Health Care Department, Municipality of Curicó, Curicó, Chile \\ ${ }^{3}$ Faculty of Psychology, University of Talca, Talca, Chile \\ ${ }^{4}$ Hospital San Juan de Dios, Curicó, Chile
}

Correspondence should be addressed to Verónica Vitriol; verovitriol@gmail.com

Received 16 June 2018; Revised 17 August 2018; Accepted 13 September 2018; Published 1 October 2018

Academic Editor: Janusz K. Rybakowski

Copyright (c) 2018 Alfredo Cancino et al. This is an open access article distributed under the Creative Commons Attribution License, which permits unrestricted use, distribution, and reproduction in any medium, provided the original work is properly cited.

\begin{abstract}
Objective. To identify the clinical and psychosocial factors associated with psychiatric comorbidity in patients consulting for depression in Primary Health Care (PHC) in Chile. Methods. 394 patients with a diagnosis of major depression being treated in a Chilean PHC were evaluated using a sociodemographic and clinical interview, the mini-international neuropsychiatric interview (MINI), a childhood trauma events (CTEs) screening, the intimate partner violence (IPV) scale, the Life Experiences Survey (LES), and the Hamilton Depression Rating Scale (HDRS). Results. Positive correlations were established between higher number of psychiatric comorbidities and severity of depressive symptoms $(r=0.358)$, frequency of CTEs $(r=0.228)$, frequency of IPV events $(\mathrm{r}=0.218)$, frequency of recent stressful life events $(\mathrm{r}=0.188)$, number of previous depressive episodes $(\mathrm{r}=0.340)$, and duration of these $(r=0.120)$. Inverse correlations were determined with age at the time of the first consultation $(r=-0.168)$, age of onset of depression $(r=-0.320)$, and number of medical comorbidities $(r=-0.140)$. Of all associated factors, early age of the first depressive episode, CTEs antecedents, and recent stressful life events explain $13.6 \%$ of total variability in psychiatric comorbidities. Conclusions. A higher prevalence of psychiatric comorbidity among subjects seeking help for depression in Chilean PHCs is associated with early onset of depression, clinical severity, chronicity, and interpersonal adversity experienced since childhood.
\end{abstract}

\section{Introduction}

Major depression is an important public health problem $[1,2]$. Worldwide, it ranks fourth among the most disabling diseases [1].

Epidemiological studies conducted in the general population [3-7] show that, among depressed patients, comorbid anxiety disorders are found in $50 \%$ of cases $[2,4,6,7]$. Compared with those who only have depression, patients with anxious-depression comorbidity develop more severe symptoms and greater chronicity, have a worse prognosis, and require different pharmacological and psychological therapeutic approaches [8].

The comorbidity of depression with other psychiatric disorders, mainly with anxiety disorders, remains a field that requires further investigation [9]. The categorization of both diagnoses has been questioned as separate nosological entities, due to the high comorbidities observed in clinical practice and genetic studies $[6,10]$. Winokur and other authors used the term "primary-secondary depression" to differentiate the clinical manifestations and the antidepressant response in patients with pure depression from patients with comorbid depression [11]. The importance of anxiety in depression is now recognized in the DSM-V [12-14], but current therapeutic guidelines for depression still do not provide a specific indication for recognition and treatment in those patients who present with such comorbidity [9].

In most countries, primary health care (PHC) is the front line for the diagnosis and treatment of depression [15]. At this level of care, the frequency of comorbid anxiety disorders 
in depressed patients can be up to $75 \%[16,17]$. However, general practitioners (GPs) frequently do not recognize anxiety in patients with depressive symptoms $[16,18]$, a fact that is associated with a worse prognosis of depression, more chronicity, higher risk of suicide, and higher health costs [1720].

In Chile, as in the world, major depression constitutes a complex public health problem [21]. Epidemiological studies conducted in the general population show that the lifetime prevalence of a major depressive episode is around 9\% [22] and the presence of depressive symptoms during the last year reaches $17.2 \%$ [21].

During the last decades, Chilean health authorities have instituted a specific program for the treatment of depression in public services [23]. According to this, 90\% of depressed Chilean patients are treated in PHC by GPs and psychosocial teams $[23,24]$. However, in this country, despite the time of implementation of this PHC program $[21,23,25]$, the evidence on the clinical recognition and the influence of psychiatric comorbidity on symptomatological severity, therapeutic response, and illness course is still scarce [21, 25].

Recent studies, carried out in a sample of depressed patients in PHC in the south-central zone of Chile [26, 27], found $89,1 \%$ had psychiatric comorbidities, most of which corresponded to the anxious spectrum. In this sample, the psychiatric comorbidity was the factor that, independent of other factors (childhood trauma, domestic violence, life stressor events, early onset of depression, and more frequency of depressive episodes), predicted the greatest clinical severity at the time of the consultation [26] and it also turned out to be the factor most associated with lower remission rates at twelve months [28].

Evidence on the characteristics associated with the comorbidity of depression with anxiety has been obtained, mainly, from clinical samples or epidemiological studies carried out in North America, Europe, and Asia [3-7]. However, there is a lack of evidence on the importance of the different factors to explain this comorbidity, specifically in PHC and in samples from Latin American countries.

Studying the above could have practical and theoretical implications. In $\mathrm{PHC}$, in practical terms, it could help to guide GPs in the search for a subgroup of depressed patients that require a differential approach. Theoretically, it could contribute to provide evidence that eventually help to understand the complex phenomenon of comorbidity in patients with depression.

The objective of this research is to identify which factors are the most important associated with greater psychiatric comorbidity at the time of consultation in Chilean PHC depressed patients.

\section{Methods}

2.1. Design. A cross-sectional quantitative study was conducted. The research was approved by the Bioethics Committees of the University of Talca and the Maule regional Health Service.
2.2. Sample. Between February and September 2014, 2978 patients older than 15 years old entered treatment for depression in 8 PHC urban clinics in the cities of Talca and Curicó, Maule region, Chile. During the first consultation, after determining their suitability to sign an informed consent, each GP invited their patients to participate in the study.

Exclusion criteria were organic cognitive disability (such as mental weakness or clues of dementia), sensory impairment (such as hearing loss), and direct referral to psychiatry service due to current severe suicide attempt and/or suspicion of bipolarity and/or psychosis upon entering.

440 patients without excluding criteria were accepted to participate in the research and after signing an informed consent, they were interviewed by a team of psychiatrists and psychologists, who proceeded to confirm the diagnosis of depressive episode based on the tenth version of the International Classification of Diseases (ICD-10) criteria [29].

MDD was confirmed in only 394 patients. The rest of them continued receiving treatment in a PHC Mental Health unit, according to their diagnosis.

Therefore, patients with a confirmed diagnosis of MDD were evaluated by the research team using the following instruments:

(1) Semistructured clinical interview, designed by the research team, which compiled (a) sociodemographic background: age of consultation, marital status, schooling, and current work activity; (b) clinical backgrounds on depressive illness: age of first depressive episode, number of depressive episodes, time of evolution of the current episode, time of evolution of the longest episode, history of attempted suicide, history of previous treatment, and history of hospitalization; (c) chronic biomedical pathologies currently under control: hypertension, diabetes, coronary pathology, arthrosis, chronic pain, cancer, Parkinson's disease, thyroid dysfunction, and so forth.

(2) Mini-International Neuropsychiatric Interview (MINI), for diagnosis of the main psychiatric disorders listed in the ICD-10 and in the fourth edition of the Diagnostic and Statistical Manual of Mental Disorders (DSM-IV) [30].

(3) Screening for CTEs, [31]: this screening delves memories before 15 years about traumatic separation from the patient's caregiver for more than a month, alcohol or drug abuse by a family member, physical abuse and physical injury associated with physical abuse, domestic violence between parents or caregivers, and sexual abuse by a relative and / or nonrelative. This instrument has been validated in Chile and has been applied in previous investigations $[32,33]$.

(4) Life Experiences Survey (LES): this is a 47-item scale that investigates life changes experienced during the previous six months, with both positive and negative meanings. A Spanish translation was used. For the purposes of this research, only stressful life events with negative connotations were considered $[34,35]$. 
(5) Questionnaire for IPV, including 12 questions that inquire about having been a victim of violence perpetrated by the intimate partner during life, taking into account the World Health Organization (WHO) definitions for physical, psychological, and sexual violence. This instrument has been used in previous studies in Chile [36].

(6) The 17-item Hamilton Depression Rating Scale (HDRS): this was used to determine the severity of the depressive symptoms [37].

2.3. Statistical Data Analysis. The statistical data analysis was performed using the fourteenth version of the Statistical Package for the Social Sciences (SPSS) program.

Univariate descriptive statistics for sociodemographic and clinical characteristics of the sample were made.

To determine the association between comorbidities and other continuous variables, bivariate Pearson correlations were performed.

Finally, to determine the highest comorbidity from the variables that would be significant, a multiple linear regression model (successive steps method) was used.

The level of significance was 0.05 .

\section{Results}

3.1. Sociodemographic and Clinical Characteristics. Table $\mathbf{1}$ shows the sociodemographic and clinical characteristics of the sample. Most of the individuals were women, in their middle age, and without a paid job and half of them were living as a couple. The average of onset of the first episode was in the third decade of life. The majority of patients presented chronic and recurrent symptoms and one-third of them with a history of attempted suicide.

3.2. Adverse Biographical Events. $82 \%$ of the sample reported at least one CTE. Any type of childhood sexual abuse was remembered by $33.1 \%$ of sample. One or more recent stressful life events were present in $92.6 \%$ of the patients and $58.1 \%$ of the studied subjects reported having suffered some type of IPV event at some time throughout their lives.

3.3. Biomedical and Psychiatric Comorbidities. 55\% of the patients presented with at least one biomedical pathology ( $21.4 \%$ only one, $18.9 \%$ two, and $33.9 \%$ three or more).

Regarding psychiatric comorbidities, $89.1 \%$ of the sample had some comorbid disorder (20.6\% only one, $20.3 \%$ two disorders, $19.5 \%$ three, and $28.6 \%$ more than 3 comorbidities). The distribution of the different psychiatric comorbidities can be seen in Table 2 .

3.4. Associations between Variables. As observed in Table 3, positive correlations were established between a greater number of psychiatric comorbidities and severity of depression according to the HDRS ( $\mathrm{r}=0.36, \mathrm{p}<0.01)$, number of depressive episodes $(\mathrm{r}=0.27, \mathrm{p}<0.01)$, duration of the longest episode $(r=0.12, p<0.05)$, number of CTEs $(r=0.23, p<0.01)$, the sum of IPV events $(\mathrm{r}=0.22, \mathrm{p}<0.01)$, and the number of recent stressful life events $(r=0.19, \mathrm{p}<0.01)$. On the other hand, inverse correlations were established with age at time of first consultation for depression $(r=-0.17, p<0.01)$, age at time of the first depressive episode $(r=-0.32, p<0.01)$, and total number of comorbid medical illnesses $(\mathrm{r}=-0.14, \mathrm{p}<0.05)$ (Table 3).

It is important to note that biomedical comorbidity was significantly associated with older age at time of first consultation for depression $(\mathrm{r}=0.59, \mathrm{p}<0.01)$ and older age at the time of the first episode $(\mathrm{r}=0.36 \mathrm{p}<0.01)$ (Table 3$)$.

Finally, using the linear regression analysis (Table 4), taking into account only the significant variables that in the simple analysis were correlated with the psychiatric comorbidity, it was established that the youngest age at the time of the first episode, the number of CTEs, and the number of recent stressful events were the most significant factors to best explain the psychiatric comorbidity. In a first model, the youngest age at the time of the first episode explained a large part of the variability $(10.4 \%)$. A second model, which includes the previous one plus the number of CTEs, explained a total of $12.2 \%$ of the variability. Finally, a third model, which includes the previous two plus the total of recent stressful life events, explained a total of $13.6 \%$ of the variability. Based on the latter model, it is possible to predict a greater number of psychiatric comorbidities by means of the following formula:

Total psychiatric comorbidities $=2,875-0,028 *$ (age at the first depressive episode $)+0,117 *$ (total CTEs $)+0,052 *$ (total recent life stressful events).

From the previous equation it follows that, in those people who have been diagnosed with depression, when the values of the independent variables (age at first depressive episode, traumatic events in childhood, and recent stressful life events) have a value equal to 0 , the total psychiatric comorbidity score will be close to 2,875 . For each unit that increases the age of onset of the first depressive episode, the psychiatric comorbidity decreases by 0.028 points, while, for each unit that increases the number of traumatic events in childhood, the psychiatric comorbidity will increase 0.117 points and for each unit that increases the number of recent vital events, the psychiatric comorbidity will increase 0.052 points.

\section{Discussion}

The high prevalence of psychiatric comorbidities found in this study is consistent with data from other studies, carried out in similar clinical samples [18, 38, 39]. This result was also associated with a younger age at the onset of depression, a greater number of depressive symptoms, and greater chronicity. These results, obtained from a Latino population, are consistent with current literature [7, 40-42].

Of all the factors analyzed in this study, the earliest age of onset of depressive symptoms was the best predictor of the increase in psychiatric comorbidity. This finding, which is consistent with the current literature [40, 41], was also observed by Davidson and Turnbull in the 80s. In their report, these authors observed that, in comparison with noncomorbid depression, depression secondary to anxiety presented not only an earlier onset of the illness, but also greater severity, chronicity, and less response to tricyclic 
TABLE 1: Sociodemographic and clinical characteristics of sample in 394 primary care patients with depression, Maule region, Chile, 2014.

\begin{tabular}{|c|c|c|}
\hline \multicolumn{3}{|c|}{ Sociodemographic Characteristics } \\
\hline & Mean & Standard deviation \\
\hline Age & 47,5 years & 15,1 \\
\hline Sex & $\mathbf{N}$ & $\%$ \\
\hline Women & 344 & 86,8 \\
\hline Scholarship & $\mathbf{N}$ & $\%$ \\
\hline Less than high school & 156 & 39.6 \\
\hline High school/partial high school & 164 & 41.6 \\
\hline College/partial college & 74 & 18.8 \\
\hline Other Features & $\mathbf{N}$ & $\%$ \\
\hline Lives with partner & 179 & 45.4 \\
\hline Lives alone & 48 & 12 \\
\hline Employed with incomes & 52 & 13.2 \\
\hline
\end{tabular}

\begin{tabular}{|c|c|c|}
\hline \multicolumn{3}{|c|}{ Clinical Characteristics Of Depression } \\
\hline & Mean & Standard deviation \\
\hline Age at the first episode (years) & 30.7 & 17.2 \\
\hline Number of depressive episodes & 3.64 & 4.2 \\
\hline Duration of the longest episode (years) & 3.58 & 7.2 \\
\hline $\begin{array}{l}\text { Depressive symptoms at baseline HDRS } \\
\text { (points) }\end{array}$ & 20 & 4.6 \\
\hline & $\mathbf{N}$ & $\%$ \\
\hline History of suicide attempt & 138 & 35 \\
\hline History of previous depression treatment & 177 & 44.9 \\
\hline \multicolumn{3}{|c|}{ Comorbidities } \\
\hline Biomedical & $\mathbf{N}$ & $\%$ \\
\hline 0 & 177 & 45 \\
\hline 1 & 84 & 21.4 \\
\hline 3 & 74 & 18,9 \\
\hline More than 3 & 59 & 15 \\
\hline Psychiatric & $\mathbf{N}$ & $\%$ \\
\hline 0 & 43 & 10,9 \\
\hline 1 & 81 & 20.6 \\
\hline 2 & 80 & 20.3 \\
\hline 3 & 77 & 19.5 \\
\hline More than 3 & 113 & 28.6 \\
\hline \multicolumn{3}{|c|}{ Adverse Biographical Events } \\
\hline $\begin{array}{l}\text { Stressful life events during previous six } \\
\text { months }\end{array}$ & $\mathbf{N}$ & $\%$ \\
\hline 0 & 30 & 7.6 \\
\hline 1 & 83 & 21.1 \\
\hline 2 & 87 & 22.1 \\
\hline 3 & 64 & 16.2 \\
\hline More than 3 & 136 & 34.6 \\
\hline $\begin{array}{l}\text { Intimate partner violence events (entire } \\
\text { life) }\end{array}$ & $\mathbf{N}$ & $\%$ \\
\hline 0 & 165 & 41.9 \\
\hline 1 & 25 & 6.4 \\
\hline 2 & 18 & 4.7 \\
\hline 3 or more & 186 & 47.2 \\
\hline
\end{tabular}


TABle 1: Continued.

\begin{tabular}{lcc}
\hline Childhood trauma events & $\mathbf{N}$ & \% \\
0 & 71 & 18 \\
1 & 67 & 17 \\
2 & 66 & 17 \\
3 & 67 & 31.2 \\
4 or more & 123 & \\
\hline
\end{tabular}

TABLE 2: Frequency of psychiatric comorbidities according to mini in 394 primary care patients with depression, Maule region, Chile, 2014.

\begin{tabular}{lll}
\hline Comorbid diagnosis & N & \% \\
\hline Post traumatic stress disorder (PTSD) & 58 & 14.8 \\
\hline Dysthymia & 79 & 20.2 \\
\hline Panic disorder & 115 & 29.3 \\
\hline Social anxiety disorder & 66 & 16.8 \\
\hline Generalized anxiety disorder (GAD) & 25.5 \\
\hline Agoraphobia & 100 & 23.5 \\
\hline Obsessive-compulsive disorder & 92 & 6.1 \\
\hline Alcohol abuse & 24 & 6.1 \\
\hline Bulimia & 24 & 7.4 \\
\hline Antisocial personality disorder & 5.6 \\
\hline
\end{tabular}

TABLE 3: Correlations between psychiatric and medical comorbidities with other variables of the study in 394 primary care patients with depression, Maule region, Chile, 2014.

\begin{tabular}{|c|c|c|c|c|}
\hline & \multicolumn{2}{|c|}{ Psychiatric comorbidities } & \multicolumn{2}{|c|}{ Biomedical comorbidities } \\
\hline & $\mathrm{R}$ & $\mathrm{p}$ & $\mathrm{R}$ & $\mathrm{p}$ \\
\hline Age at time of first consultation for depression & -0.17 & 0.01 & 0.59 & 0.01 \\
\hline Age at time of the first depressive episode & -0.32 & 0.01 & 0.36 & 0.01 \\
\hline Number of previous depressive episodes & 0.34 & 0.01 & 0.12 & 0.01 \\
\hline Duration of the longest depressive episode & 0.12 & 0.05 & 0.1 & NS \\
\hline Number of biomedical comorbidities & -0.14 & 0.05 & 1 & - \\
\hline Number of psychiatric comorbidities & 1 & - & -0.14 & 0.01 \\
\hline Number of childhood trauma events & 0.23 & 0.01 & -0.03 & NS \\
\hline Number of intimate partner violence events & 0.22 & 0.01 & 0.07 & NS \\
\hline Number of stressful life events during the last 6 months & 0.19 & 0.01 & -0.12 & 0.05 \\
\hline Severity of depressive symptoms & 0.36 & 0.01 & -0.02 & NS \\
\hline
\end{tabular}

NS: no significant value.

treatment and electroconvulsive therapy [43]. Other authors have found evidence that atypical depression, or depression with atypical features as it has been known in the DSM-IV, is associated with higher rates social anxiety disorder, earlier age of onset, and higher severity of the illness when compared to nonatypical depression [44].

The evidence that anxiety-depression comorbidity implies a different profile of depressive patients is now included in the DSMV $[13,14]$. Current research shows that these patients need a more intensive serotonergic treatment [8]. Considering that anxious comorbidity is underdiagnosed in patients with depression $[16,17]$, our results give more evidence on the importance of performing an active investigation of anxious symptomatology in $\mathrm{PHC}$ depressed patients, mainly when depressive manifestations start early. Evidence shows that social anxiety begins earlier in life, followed by generalized anxiety and panic disorders, and finally by posttraumatic stress disorder [45].

Additionally, in this sample, the highest psychiatric comorbidity was associated with all the forms of interpersonal biographical trauma. In this sample we found a high frequency of CTEs, especially sexual abuse [26, 27, 46]. These backgrounds were the second factor-after younger age at the time of the first depressive episode-that predicted greatest psychiatric comorbidity in this sample. On the other hand, according to the results of this study, the antecedents of intimate partner violence (IPV) and recent stressful life events are factors associated with depression comorbidity that should also be considered. 
TABLE 4: Linear regression model of significant variables that best explain the psychiatric comorbidity in 394 primary care patients with depression, Maule region, Chile, 2014.

\begin{tabular}{llccc}
\hline Model & $\mathrm{R}$ & $\mathrm{R}^{2}$ & Corrected $^{2}$ & Typical error of the estimation \\
\hline 1 & $-0.327^{\mathrm{a}}$ & 0.107 & 0.104 & 1.58 \\
\hline 3 & $0.358^{\mathrm{b}}$ & 0.128 & 0.122 & 1.65 \\
\hline
\end{tabular}

a. Predictor variables: (constant), younger age at the time of the first depressive episode.

b. Predictor variables: (constant), younger age at the time of the first depressive episode, number of childhood trauma events.

c. Predictor variables: (constant), younger age at the time of the first depressive episode, number of childhood trauma events, and number of recent stressful life events.

Regarding the impact of history of CTEs on depression $[7,42,46]$, the findings of this study are in the same line of current literature [47-49]. According to the evidence accumulated during the last 30 years [46-49], CTEs constitute a vulnerability factor for development of adult psychopathology such as depression [50]. In addition, patients affected by depression with CTEs often develop complex clinical manifestations, which are characterized by the early onset of depression, presence of psychiatric comorbidity, recurrent MDD, increased suicide risk, and poor response to treatments validated for depression [51-54]. Most of these clinical characteristics were also associated with greater psychiatric comorbidity in this sample.

The clinical complexity presented by patients with adult psychopathology and history of CTEs is an expression of neurobiological changes in epigenetics, neuro-immunoendocrine systems and neurotransmission, and specific toxicity in brain areas, as a consequence of the exposure to damaging stressful experiences during a window of great susceptibility in the development of the mental system [4649].

In this sense, according to our data and the current knowledge, it is possible to posit that the association between anxiety-depression comorbidity and early onset of depression may be associated with history of CTEs, which in turn is based on vulnerability to stress. In these patients this vulnerability may favor first the development of anxious symptoms followed by the onset of a depressive disorder.

As said above, for several authors, patients with depression and history of CTEs constitute a different profile of depressive patients who should be recognized in clinical practice [48, 49]. However, as psychiatric comorbidities, traumatic biographies are not routinely investigated when subjects consult for depression $[55,56]$ and the recognition of the deleterious consequences of child maltreatment is not even incorporated in psychiatric nosology [56].

Based on our data and other studies [6, 46, 51], we posit that psychiatric comorbidity and CTEs are factors that could be present in the same subtype of depressive patients. Additionally, our research team has also found associations between specific CTEs and specific comorbid anxiety disorders in depressed patients: psychological abuse was associated with social phobia, and sexual abuse was associated with posttraumatic stress disorder and panic disorder [27]. Taking into account the above, psychiatric comorbidity and CTEs are factors that should be inquired in PHC depressed patients, especially when depressive manifestations start early. These patients may require differentiated pharmacological treatment and a differentiated integral psychological clinical approach [8].

Another important finding in our study was the fact that, in this sample, we were unable to establish a relationship between biomedical pathology and childhood trauma history. This result was unexpected considering the Adverse Childhood Study (ACES) findings [57-59] and could be explained considering that the instrument used in this research only considered some of the childhood adverse events investigated in the ACES. The lack of association between CTEs and biomedical comorbidities in this sample can also explain the result of this study with respect to the inversely significant relationship between psychiatric comorbidity and biomedical comorbidity.

Among the limitations of this work is the fact that the instrument used to diagnose psychiatric comorbidities punctually investigated current and nonhistorical diagnoses, and it excluded diagnoses such as borderline personality disorder and somatoform disorders. On the other hand, the CTEs were retrospectively investigated and, as already noted, only some adverse events were considered. Childhood negligence must be incorporated in future studies [38].

Among the strengths of this study, we can point out that the diagnostic instruments were administered by professionals with years of experience in mental health, which allowed them to access very confidential information and to perform a comprehensive and standardized evaluation of the different psychiatric comorbidities.

In summary, as the available evidence shows, our results confirm that the high prevalence of psychiatric comorbidity in patients who consult for depression in PHC is associated with a subgroup of patients whose depression occurs with greater severity, earlier onset of depressive illness, chronicity, and exposure to multiple interpersonal stressors since childhood.

Taking into account the fact that current therapeutic guidelines for depression still do not provide a specific indication for recognition and treatment in those patients who present comorbidities [9] and considering that psychiatric comorbidities and psychosocial factors associated are often underdiagnosed and not adequately treated in the PHC [16, 17], this study gives more evidence on the importance to 
incorporate new strategies, aimed at the recognition and adequate treatment of comorbidities and the factors associated in depressed patients consulting in PHC.

\section{Data Availability}

(1) The database used to support the findings of this study is included in the final form of the project "Factors associated with the different evolutions by patients admitted to GES depression in Primary Care Region VII: following a cohort", CONICYT FONIS Project SA13/20135. You can access to this form contacting the mail fonis@conicyt.cl. (2) Most of the data used in this article are included in tables in the main article. (3) Also the database used to support the findings of this study is included in PDF within the supplementary information file. (4) Finally the database used to support the findings of this study is available from the corresponding author upon request.

\section{Disclosure}

This article shows some results of CONICYT FONIS Project SA13/20135 "Factors associated with the different evolutions by patients admitted to GES depression in Primary Care Region VII: following a cohort".

\section{Conflicts of Interest}

Researchers declare no conflicts of interest and they guarantee that the funding from the FONIS did not influence in any way the results of the present study.

\section{Supplementary Materials}

Regarding the supplementary materials submitted with our manuscript, this corresponded to the database of the CONICYT FONIS Project SA13/20135. The data that we used in this paper are part of this project. We send this database in PDF as part of the data availability but this material cannot be published with the manuscript. (Supplementary Materials)

\section{References}

[1] World Health Organization, "The Global Burden of Disease: 2004 Update," Geneva, Switzerland: World Health Organization; 2008; http://www.who.int/healthinfo/global_burden_disease/GBD_report_2004update_full.pdf.

[2] R. C. Kessler, K. R. Merikangas, and P. S. Wang, "Prevalence, Comorbidity, and Service Utilization for Mood Disorders in the United States at the Beginning of the Twenty-first Century," Annual Review of Clinical Psychology, vol. 3, no. 1, pp. 137-158, 2007.

[3] F. Lamers, P. van Oppen, H. C. Comijs et al., "Comorbidity patterns of anxiety and depressive disorders in a large cohort study: the Netherlands Study of Depression and Anxiety (NESDA)," Journal of Clinical Psychiatry, vol. 72, no. 3, pp. 342-348, 2011.

[4] L. Davis, A. Uezato, J. M. Newell, and E. Frazier, "Major depression and comorbid substance use disorders," Current Opinion in Psychiatry, vol. 21, no. 1, pp. 14-18, 2008.
[5] W. U. Zhiguo and F. Yiru, "Comorbidity of depressive and anxiety disorders: challenges in diagnosis and assessment," Shangai Arch of Psychiatry, vol. 26, no. 4, pp. 227-231, 2014, http://dx.doi.org/10.3969/j.issn.1002-0829.2014.04.006.

[6] R. Kessler, A. Meron, K. Shear, and H. Ulrich-Wittchen, "Epidemiology of anxiety disorders," Behavorial Neurobiology of Anxiety and his Treatments, vol. 2, pp. 21-35, 2009.

[7] J. M. Cyranowski, L. L. Schott, H. M. Kravitz et al., "Psychosocial features associated with lifetime comorbidity of major depression and anxiety disorders among a community sample of midlife women: The SWAN mental health study," Depression and Anxiety, vol. 29, no. 12, pp. 1050-1057, 2012.

[8] J. D. Coplan, "Treating comorbid anxiety and depression: Psychosocial and pharmacological approaches," World Journal of Psychiatry, vol. 5, no. 4, p. 366, 2015.

[9] L. Dell' Osso and S. Pini, "What did we learn from research on comorbidity in Psychiatry? Advantages and limitations in the forthcoming DSMV Era," Clinical Practice \& Epidemiology in Mental Health, vol. 8, pp. 180-184, 2012.

[10] B. Bandelow, D. Baldwin, M. Abelli et al., "Biological markers for anxiety disorders, OCD and PTSD - a consensus statement. Part I: Neuroimaging and genetics," The World Journal of Biological Psychiatry, vol. 17, no. 5, pp. 321-365, 2016.

[11] G. Winokur, "The concept of secondary depression and its relationship to comorbidity," Psychiatric Clinics of North America, vol. 13, no. 4, pp. 567-583, 1990.

[12] R. Gaspersz, F. Lamers, J. M. Kent et al., "Longitudinal predictive validity of the DSM-5 anxious distress specifier for clinical outcomes in a large cohort of patients with major depressive disorder," Journal of Clinical Psychiatry, vol. 78, no. 2, pp. 207213, 2016.

[13] American Psychiatric Association, Diagnostic and Statistical Manual of Mental Disorders, American Psychiatric Association, Arlington, VA, USA, 5th edition, 2013.

[14] K. Rorie, "Major depressive disorder in the primary care setting," The Journal of Family Practice, vol. 64, p. 9, 2015.

[15] E. Aragonès, J. Lluís Piñol, and A. Labad, "Comorbilidad de la depresión mayor con otros trastornos mentales comunes en pacientes de atención primaria," Atención Primaria, vol. 41, no. 10, pp. 545-551, 2009.

[16] R. M. A. Hirschfeld, "The comorbidity of major depression and anxiety disorders: Recognition and management in primary care," Primary Care Companion to the Journal of Clinical Psychiatry, vol. 3, no. 6, pp. 244-254, 2001.

[17] L. Culpepper, "Managing depression in primary care: achieving remission," Primary Care Companion to the Journal of Clinical Psychiatry, vol. 8, no. 2, pp. 88-97, 2006.

[18] R. H. Howland, A. John Rush, S. R. Wisniewski et al., "Concurrent anxiety and substance use disorders among outpatients with major depression: Clinical features and effect on treatment outcome," Drug and Alcohol Dependence, vol. 99, no. 1-3, pp. 248-260, 2009.

[19] M. Fava, A. J. Rush, J. E. Alpert et al., "Difference in treatment outcome in outpatients with anxious versus nonanxious depression: A STAR ${ }^{*} \mathrm{D}$ report," The American Journal of Psychiatry, vol. 165, no. 3, pp. 342-351, 2008.

[20] Z. Wu, J. Chen, C. Yuan et al., "Difference in remission in a Chinese population with anxious versus nonanxious treatmentresistant depression: A report of OPERATION study," Journal of Affective Disorders, vol. 150, no. 3, pp. 834-839, 2013. 
[21] L. Salvo, "Magnitude, impact and recommended management for depression, with reference to Chile," Revista Médica de Chile, vol. 142, pp. 1157-1164, 2014.

[22] B. Vicente, R. Kohn, P. Rioseco, S. Saldivia, I. Levav, and S. Torres, "Lifetime and 12-month prevalence of DSM-III$\mathrm{R}$ disorders in the Chile psychiatric prevalence study," The American Journal of Psychiatry, vol. 163, no. 8, pp. 1362-1370, 2006.

[23] R. Araya, R. Alvarado, R. Sepúlveda, and G. Rojas, "Lessons from scaling up a depression treatment program in primary care in Chile," Revista Panamericana de Salud Pública, vol. 32, no. 3, pp. 234-240, 2013.

[24] MINSAL, "Clinical guide for the treatment of people with depression," Ministry of Health, Government of Chile, 2013.

[25] R. Alvarado, J. Vega, G. Sanhueza, and M. G. Muñoz, "Evaluación del programa para la detección, diagnóstico y tratamiento Integral de la depresión en atención primaria en Chile," Revista Panamericana de Salud Pública, vol. 18, no. 4-5, pp. 278-286, 2005.

[26] V. Vitriol, A. Cancino, S. Ballesteros, S. Potthoff, and C. Serrano, "Factors Associated With Greater Severity of Depression in Chilean Primary Care Patients," The Primary Care Companion for CNS Disorders, vol. 19, no. 3, 2017.

[27] V. Vitriol, A. Cancino, M. Leiva-Bianchi et al., "Childhood trauma and psychiatric comorbidities in patients with depressive disorder in primary care in Chile," Journal of Trauma \& Dissociation, vol. 18, no. 2, pp. 189-205, 2017.

[28] V. Vitriol, A. Cancino, C. Serrano, S. Ballesteros, and S. Potthoff, "Remission in Depression and Associated Factors at Different Assessment Times in Primary Care in Chile," Clinical Practice \& Epidemiology in Mental Health, vol. 14, no. 1, pp. 78-88, 2018.

[29] "Clasificación Estadística International de Enfermedades y Problemas relacionados con la salud," Décima Revisión, Washington DC: OPS 1995.

[30] D. V. Sheehan, Y. Lecrubier, K. H. Sheehan et al., "The miniinternational neuropsychiatric interview (M.I.N.I.): the development and validation of a structured diagnostic psychiatric interview for DSM-IV and ICD-10," Journal of Clinical Psychiatry, vol. 59, no. 20, pp. 22-33, 34-57, 1998.

[31] R. D. Marshall, F. R. Schneier, S.-H. Lin, H. B. Simpson, D. Vermes, and M. Liebowitz, "Childhood trauma and dissociative symptoms in panic disorder," The American Journal of Psychiatry, vol. 157, no. 3, pp. 451-453, 2000.

[32] C. Cuneo, I. Gonzalez, M. Jara et al., Validación Externa de la Escala de Trauma de Marshall. Trauma Infanto-Juvenil y Psicopatología Adulta, Chapter 9, Universidad de Los Andes, 1st edition, 2005.

[33] V. G. Vitriol, S. T. Ballesteros, R. U. Florenzano, K. P. Weil, and D. F. Benadof, "Evaluation of an outpatient intervention for women with severe depression and a history of childhood trauma," Psychiatric Services, vol. 60, no. 7, pp. 936-942, 2009.

[34] I. G. Sarason, J. H. Johnson, and J. M. Siegel, "Assessing the impact of life changes: development of the life experiences survey," Journal of Consulting and Clinical Psychology, vol. 46, no. 5, pp. 932-946, 1978.

[35] D. Páez et al., Salud Mental y Factores Psicosociales, Fundamentos, Madrid, Spain, 1986.

[36] E. Illanes, L. Bustos, B. Vizcarra, and S. Muñoz, "Violencia y factores sociales en mujeres de la ciudad de Temuco," Revista Médica de Chile, vol. 135, no. 3, pp. 326-334, 2007.
[37] J. A. Ramos-Brieva and A. Cordero-Villafafila, "A new validation of the Hamilton Rating Scale for depression," Journal of Psychiatric Research, vol. 22, no. 1, pp. 21-28, 1988.

[38] P. Thaipisuttikul, P. Ittasakul, P. Waleeprakhon, P. Wisajun, and S. Jullagate, "Psychiatric comorbidities in patients with major depressive disorder," Neuropsychiatric Disease and Treatment, vol. 10, no. 10, pp. 2097-2103, 2014.

[39] M. Fava, A. J. Rush, J. E. Alpert et al., "What clinical and symptom features and comorbid disorders characterize outpatients with anxious major depressive disorder: A replication and extension," The Canadian Journal of Psychiatry, vol. 51, no. 13, pp. 823-835, 2006.

[40] R. de Graaf, R. V. Bijl, F. Smit, W. A. M. Vollebergh, and J. Spijker, "Risk factors for 12-month comorbidity of mood, anxiety, and substance use disorders: Findings from the Netherlands mental health survey and incidence study," The American Journal of Psychiatry, vol. 159, no. 4, pp. 620-629, 2002.

[41] R. de Graaf, R. Bijl, M. Ten Have, A. Beekman, and W. Vollebergh, "Pathways to the transition of pure mood, anxiety and substance use disorders into comorbid conditions in a longitudinal population-based study," Journal of Affective Disorders, vol. 82, no. 3, pp. 515-523, 2015.

[42] S. M. Meier, L. Petersen, M. Mattheisen, O. Mors, P. B. Mortensen, and T. M. Laursen, "Secondary depression in severe anxiety disorders: A population-based cohort study in Denmark," The Lancet Psychiatry, vol. 2, no. 6, pp. 515-523, 2015.

[43] J. Davidson, C. D. Turnbull, and R. D. Miller, "A comparison of inpatients with primary unipolar depression and depression secondary to anxiety," Acta Psychiatrica Scandinavica, vol. 61, no. 5, pp. 377-386, 1980.

[44] A. Koyuncu, E. Ertekin, B. A. Ertekin et al., "Relationship between atypical depression and social anxiety disorder," Psychiatry Research, vol. 225, no. 1-2, pp. 79-84, 2015.

[45] J. W. Smoller, E. Gardner-Schuster, and M. Misiaszek, "Genetics of anxiety: Would the genome recognize the DSM?" Depression and Anxiety, vol. 25, no. 4, pp. 368-377, 2008.

[46] V. Vitriol, A. Cancino, M. Leiva-Bianchi et al., "Depresión adulta y experiencias infantiles adversas: evidencia de un subtipo depresivo complejo en consultantes de la atención primaria en Chile," Revista Médica de Chile, vol. 145, no. 9, pp. 1145-1153, 2017.

[47] M. H. Teicher and J. A. Samson, "Childhood maltreatment and psychopathology: A case for ecophenotypic variants as clinically and neurobiologically distinct subtypes," The American Journal of Psychiatry, vol. 170, no. 10, pp. 1114-1133, 2013.

[48] M. H. Teicher and J. A. Samson, "Annual Research Review: Enduring neurobiological effects of childhood abuse and neglect," Journal of Child Psychology and Psychiatry, vol. 57, no. 3, pp. 241-266, 2016.

[49] C. B. Nemeroff, "Paradise Lost: The Neurobiological and Clinical Consequences of Child Abuse and Neglect," Neuron, vol. 89, no. 5, pp. 892-909, 2016.

[50] C. B. Nemeroff and E. Binder, "The preeminent role of childhood abuse and neglect in vulnerability to major psychiatric disorders: Toward elucidating the underlying neurobiological mechanisms," Journal of the American Academy of Child and Adolescent Psychiatry, vol. 53, no. 4, pp. 395-397, 2014.

[51] V. Vitriol, A. Cancino, K. Weil, C. Salgado, M. A. Asenjo, and S. Potthoff, "Depression and psychological trauma: An overview integrating current research and specific evidence of studies in the treatment of depression in public mental health services in Chile," Depression Research and Treatment, pp. 1-10, 2014. 
[52] C. Z. Bernet and M. B. Stein, "Relationship of childhood maltreatment to the onset and course of major depression in adulthood," Depression and Anxiety, vol. 9, no. 4, pp. 169-174, 1999.

[53] J. G. F. M. Hovens, E. J. Giltay, J. E. Wiersma, P. Spinhoven, B. W. J. H. Penninx, and F. G. Zitman, "Impact of childhood life events and trauma on the course of depressive and anxiety disorders," Acta Psychiatrica Scandinavica, vol. 126, no. 3, pp. 198-207, 2012.

[54] J. Korkeila, J. Vahtera, H. Nabi et al., "Childhood adversities, adulthood life events and depression," Journal of Affective Disorders, vol. 127, no. 1-3, pp. 130-138, 2010.

[55] S. Sigurdardottir and S. Halldorsdottir, "Repressed and silent suffering: Consequences of childhood sexual abuse for women's health and well-being," Scandinavian Journal of Caring Sciences, vol. 27, no. 2, pp. 422-432, 2013.

[56] B. van der Kolk, "Commentary: The devastating effects of ignoring child maltreatment in psychiatry- a commentary on Teicher and Samson," Journal of Child Psychology and Psychiatry, vol. 57, no. 3, pp. 267-270, 2016.

[57] R. F. Anda, V. J. Felitti, J. D. Bremner et al., "The enduring effects of abuse and related adverse experiences in childhood: a convergence of evidence from neurobiology and epidemiology," European Archives of Psychiatry and Clinical Neurosciences, vol. 256, no. 3, pp. 174-186, 2006.

[58] M. A. Bellis, H. Lowey, N. Leckenby, K. Hughes, and D. Harrison, "Adverse childhood experiences: retrospective study to determine their impact on adult health behaviours and health outcomes in a UK population," Journal of Public Health, vol. 36, no. 1, pp. 81-91, 2013.

[59] P. Cuijpers, F. Smit, F. Unger, Y. Stikkelbroek, M. ten Have, and R. de Graaf, "The disease burden of childhood adversities in adults: A population-based study," Child Abuse \& Neglect, vol. 35, no. 11, pp. 937-945, 2011. 


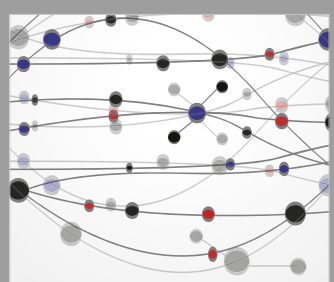

The Scientific World Journal
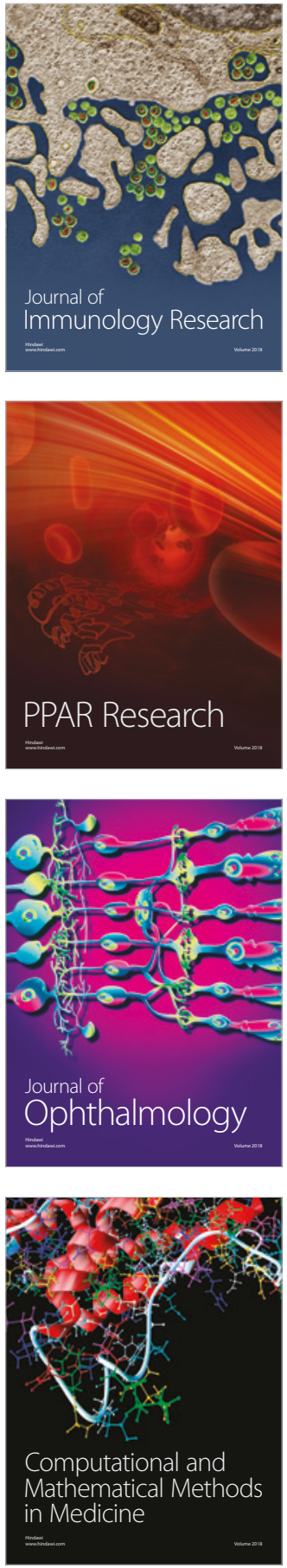

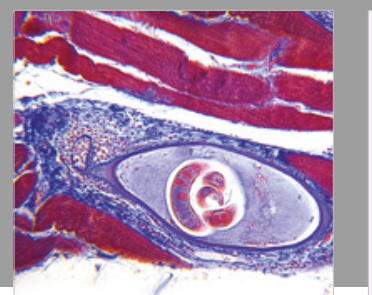

Gastroenterology Research and Practice

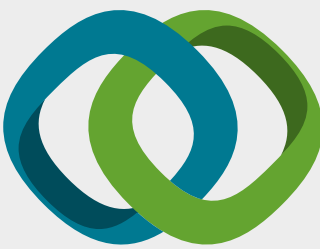

\section{Hindawi}

Submit your manuscripts at

www.hindawi.com
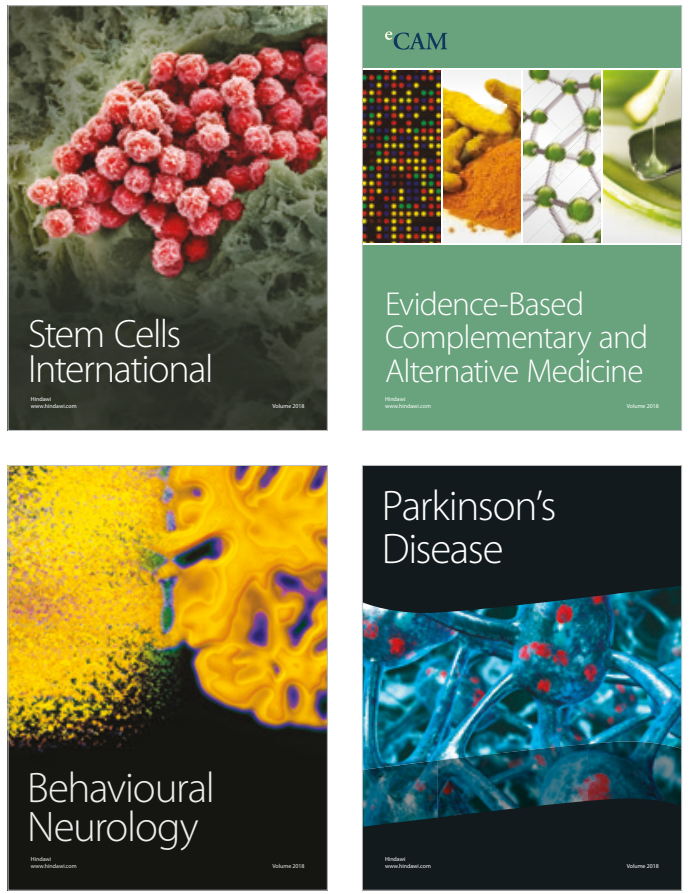

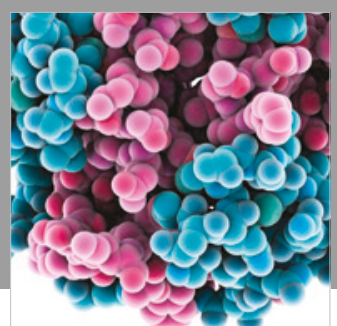

ournal of

Diabetes Research

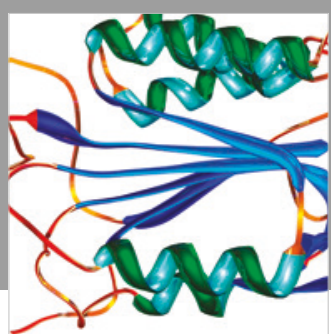

Disease Markers
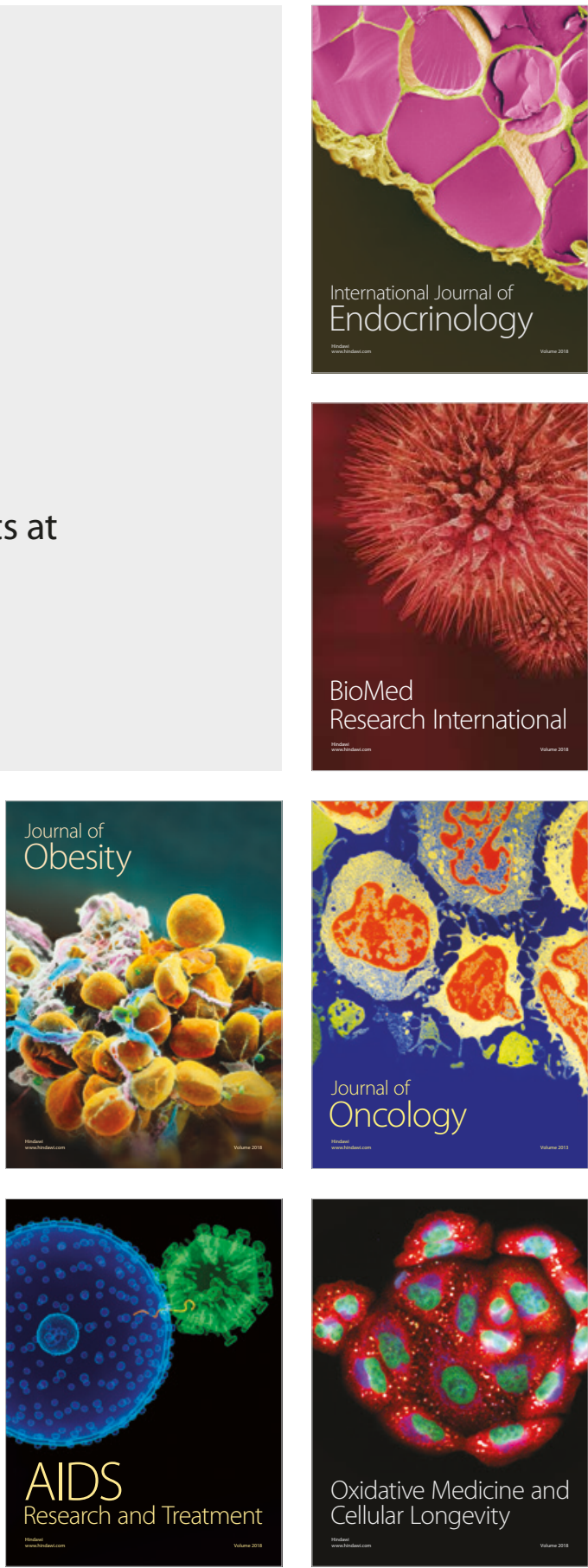